llevaría a mayor extremo: la celebridad es, a sus ojos, la única grandeza.

No cabe imaginar para nuestra época un supuesto más halagüeño. Gracias a él ciñen la máxima corona sus héroes reprensentativos, futbolistas y boxeadores. Pero hay todavía una consecuencia más general y decisiva. Si el grande hombre lo es sólo en virtud de su celebridad, el varón medio halla en la biografía de aquel este minúsculo consuelo: el grande hombre no existe. Porque la celebridad no es un atributo sustantivo, sino un don que otorga la mayoría, esto es los hombres medios juntos. Por tanto, al grande hombre lo hacen los hombres medios.

Ese era por lo menos su secreto deseo. Un género literario que yacía hasta ahora en segundo término se lo ha descubierto y servido discretamente. El viene a decir que los héroes vivieron sometidos a la común gravitación, que la trayectoria de sus existencias fué el desarrollo de las penalidades, las misegrias, las caídas y las desconcertantes alucinaciones de toda vida humana. Y como esto no deja de ser verdad, y casualmente es la parte de la verdad que interpreta y satisface a la criatura media de nuestra época, he aquí que la biografía salta de pronto al primer plano de preferencia entre la producción literaria.

El caso no tenía por qué parecer extraño. De cuanto la masa contemporánea ha hecho en su propio ámbito, lo más característico es la anulación de las minorías selectas, el desalojamiento de los individuos mejores. Resulta lógica una postura análoga respecto a las minorías y a las individualidades más altas de otras épocas. La nuestra, habiéndose cortado la cabeza a sí misma, quiere darse el placer demócrata de ver a las anteriores decapitadas.-R. C A B R E R A M É N DEZ.

\title{
PRIVILEGIOS DE LA OPERA RUSA
}

[ LEGADA última en la Historia, la escuela rusa representa la evolución musical más característica de la hora presente. Mucho más que en la música de cámara, es en la música escénica donde se manifiesta. Es tal la perfección de la ópera rusa que se puede decir que la inspiración musical se exterioriza en ella no solamente por medio de los instrumentos y de la voz, sino también por la decoración y la danza, de tal modo que el arte no se encuentra allí limitado 
sino que logra su finalidad por todos los medios que se le of recen.

He aquí una singularidad tan notable que viene a ser única. $Y$ si la 6pera rusa prima hoy sobre todas las producciones escénicas, conviene saber a qué maravillosos privilegios se debe su triunfo.

La ópera rusa nació perfecta. Surgió en pleno romanticismo, no conoció tanteos ni mediocridades: las escuelas europeas habían creado para ella su propia técnica. Por lo demás, no les pidió prestado más que eso, y si por excepción se pueden anotar, especialmente en Rimsky Korsakoff, reminiscencias wagnerianas, él fué el golpe profundamente original, profundamente eslavo.

Por un curioso retorno, esta música sabia, olvidada de dilettantes que el sólo vértigo transforma en profesionales de la partitura, posee un carácter nacional mucho más acentuado que la música rusa que la precedía, la cual fué directamente inspirada en el arte bizantino.

Era asimsimo una música patriótica que quisieron fundar Glinka y Mili Balakirew. César Cui, Borodin, Mussorgsky obedecieron al mismo sentimiento.

Pero estas palabras no deben prestarse a confusión.

En nuestro espíritu occidental, el sentimiento patriótico reviste una apariencia militar y guerrera que conduce a que toda obra emanada de él no sea más que una fanfarria de trompetas y de cantos de soldados. Fn cambio el patriotismo de los músicos rusos procede de un amor íntimo del terruño, de una especie de pasión mística por Rusia.

Los libretos de sus óperas son sacados del fondo común del folklore. Y gracias a la introducción de aires populares en el tema musical, ellos obtienen el pleno valor de su realización.

Este punto esencial para el estudio de la música rusa exige que nos detengamos en él.

Cada nación posee sus aires populares, es decir, sus canciones espontáneamente nacidas en el pueblo, sea que ellas hayan sido realmente producidas por la imaginación colectiva que encuentra allí un medio cómodo de expresión para sentimientos imprecisos, sea que, primitivamente compuestas por un autor desconocido, hayan sido enriquecidas con los cambios que las generaciones, no obstante respetarlas, les hayan introducido.

Gracias al proceso de su formación, la canción popular adquiere el valioso atributo de ser una imagen exacta del alma popular, reflejando de este modo los rasgos perdurables del carácter nacional. 
Es así cómo la canción francesa fué, según las épocas, frívola, amorosa, gallarda, licenciosa, pero en el fondo siempre bastante superficial y no alcanzó a la pasión, sino en el frenesí de los cantos revolucionarios.

La canción rusa es siempre mística, porque el alma rusa, ávida de lo desconocido, en un paisaje monótono, ebria de la similitud de la estepa, e impregnada de su desesperanza, busca quién sabe qué refugios en los caminos abiertos a su ensueño. El aire popular conoce esta grandeza del pensamiento disuelto en el sueño.

Una pena enfermiza arrastra allí su tristeza para que estalle en seguida la violencia de la sensualidad. El misterio del Oriente se casa con la puerilidad, la barbarie con el candor, la brutalidad con la inocencia.

Desde luego, el compositor encuentra en este aire no un motivo que desarrollar o como un llamado a un conocimiento preestablecido, sino un modo de expresión de su propio pensamiento y como un recuerdo anticipado de su personal meditación.

Para un compositor francés existe entre su inspiración y el aire popular, tal diferencia de calidad, que si él recurre a este aire popular y lo introduce en su obra, no logrará sịno como paréntesis o como ornamento facticio, agregado al desarrollo melódico: la canción no entra en la línea de la obra.

Considérese bajo este ángulo, por ejemplo, la obra de Charpentier. Inmediatamente aparece el carácter adicional de sus incursiones en el terreno de lo popular.

Cosa muy diferente ocurre con el compositor ruso.

Lo que le da el aire popular no es lo pintoresco, lo accidental, lo ocasional, es el eco de su pensamiento en la masa, y la labor de composición que tiene que hacer no es más que la transposición de lo colectivo a lo personal.

Si el aire popular se nos presenta, pues, tan claramente en la ópera rusa, aunque está íntimamente ligado a su estructura, es simplemente porque el autor lo ha reducido a notas y lo ha orquestado.

De este modo lo habrá hecho suyo, puesto que interpreta lo más característico de su temperamento y puesto que ese aire es, por el misticismo particular de la raza, el punto de conjunción de la inspiración de este compositor y de todo el que sobre la tierra piense, ame y sufra en eslavo.

De ahí el carácter nacional de la 6́pera rusa. Posee, pues, el mágico poder de ser el fruto-en la más personal de sus manifestaciones, hasta en Kimsky Korsakoff-mucho menos de un hombre que de todo un pueblo, de todo un país. 
Se ha hecho notar con frecuencia la comunion que unifica en esta 6́pera la música, los protagonistas y los coros. Hay allí, ciertamente, un efecto espontáneo de la pasión con la cual músicos, artistas y coristas, abdicando toda personalidad, sirven a la obra.

Pero también se puede ver en esto, en cierto modo, la resultante lejana del origen común de la ópera. Tanto en su formación como en su expresión, la característica más poderosa de la 6 pera rusa es no ser individual.

Tómese una ópera italiana. ¿Qué se encuentra en ella? La habilidad técnica de un hombre cualquiera; una virtuosidad; más exactamente, una acrobacia de composición al servicio de un sentimentalismo brumoso; la expresión de un individuo que no busca sino brillar, causar estupor.

En la ópera rusa un pueblo ha puesto sus alegrías, sus penas, sus sueños. ¿Debemos sorprendernos si ésta nos conmueve más que aquella?

Hay mucho que decir sobre el dinamismo de esta música rusa, sobre su potencia de ideal. Que nos baste por ahora señalar cómo son introducidos a la obra, para encontrar en ella su forma adecuada, al mismo tiempo que-le comunican su verdadera grandeza, los elementos del folklore.- M. DE N I C O L A Y. (Traducido por J. M. S.)

\section{LA VIDA DE BOLIVAR}

Al DELANTANDOSE al Centenario que celebraremos dentro de poco, los señores Georges Lafond y Gabriel Tersane acaban de publicar en París, bajo el título de $L a$ Vie de Bolivar, un estudio particularmente importante que pone de relieve una vez más ese don maravilloso de la síntesis que caracteriza a los escritores franceses, educados en la escuela del método y de la visión superior.

Cuando escribimos en la América Latina sobre nuestra historia ocurre a menudo que el entusiasmo o el rencor desorbitan los sucesos, alterando la significación de las figuras, enconando las rivalidades, enredando a veces los hilos de la acción hasta ahogar el relato en digresiones superfluas que quiebran sin beneficio alguno la línea, que debió ser inexorable, de la verdad. La fiebre localista suele sacrificar a éstos en beneficio de aquéllos, según la filiación de quien reconstruye el pasado: $y$ en todo momento prima el criterio de la ciudad, de la pro- 